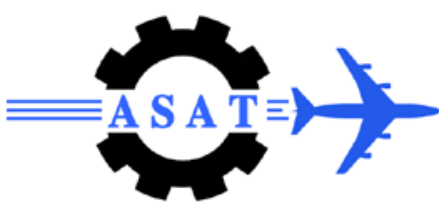

\title{
P-8A Poseidon: An Innovative Strategy for the Acquisition, Design, Manufacture, and Integration of Military Derivative Aircraft
}

\author{
Hatem H. Daken ${ }^{*}$, Ph.D.
}

\begin{abstract}
The P-8A Poseidon, previously referred to as the MMA, is a long-range antisubmarine warfare, anti-surface warfare, intelligence, surveillance and reconnaissance aircraft. It possesses an advanced mission system that ensures maximum interoperability in the future battle space. Capable of broad-area maritime and littoral operations, the P-8A will influence how the U.S. Navy's maritime patrol and reconnaissance forces train, operate, and deploy ${ }^{1}$. This article discusses the innovative strategies that were employed in its acquisition, design, manufacture, and integration.
\end{abstract}

Keywords: P-8A Poseidon, Military Derivative Aircraft

\section{Introduction}

Large commercial aircraft have often been selected as platforms to accomplish high value combat-related missions without incurring the costs of a dedicated design. They provide state-of-the-art performance where the mission profiles are similar to the commercial application. These mission profiles usually entail long range or long endurance flights at high altitude and steady cruise conditions with limited need for maneuverability or special takeoff and landing performance.

Although considerable effort may be necessary to modify the design for the Service application, the costs for developing these platforms have already been borne by the manufacturer in creating the commercial design. The intent is to gain as much benefit from the commercial platform as possible ${ }^{2}$.

Current examples of these aircraft include, but not limited to, the KC-10 Extender (McDonnell Douglas DC-10-30), the KC-135R Stratotanker (Boeing 367-80 was the basic design for the commercial 707 passenger plane as well as the KC-135A), the RC-135V/W Rivet Joint aerial reconnaissance aircraft (KC-135), the E-3 Sentry Airborne Warning and Control System AWACS (Boeing 707-320B), the E-8C Joint Surveillance Target Attack Radar System Joint STARS (Boeing 707-300), the 737 AEW\&C Wedgetail (Boeing 737700), the Hawker Siddeley Nimrod MRA4 (de Havilland Comet), VC-25 Air Force One (Boeing 747-200B), and the AirBorne Laser aircraft ABL (747-400F). Figure 1 depicts these aircraft in the same sequence above from left to right and top to down.

Senior Structural Analysis Scientist/Engineer, Boeing Commercial Airplanes, The Boeing Company, Seattle, WA, USA, hatemdaken@aol.com 
The P-8A Poseidon Program addresses the need to sustain and improve maritime and littoral intelligence, surveillance, and reconnaissance (ISR) capabilities for U.S. naval forces in traditional, joint, and coalition roles to counter changing and emerging threats. The P-8A Poseidon is intended to participate in missions involving armed maritime and littoral surveillance, sea control and access, land targeting and strike, and command and control tasks assigned to the Naval Air Patrol and Reconnaissance community ${ }^{3}$.

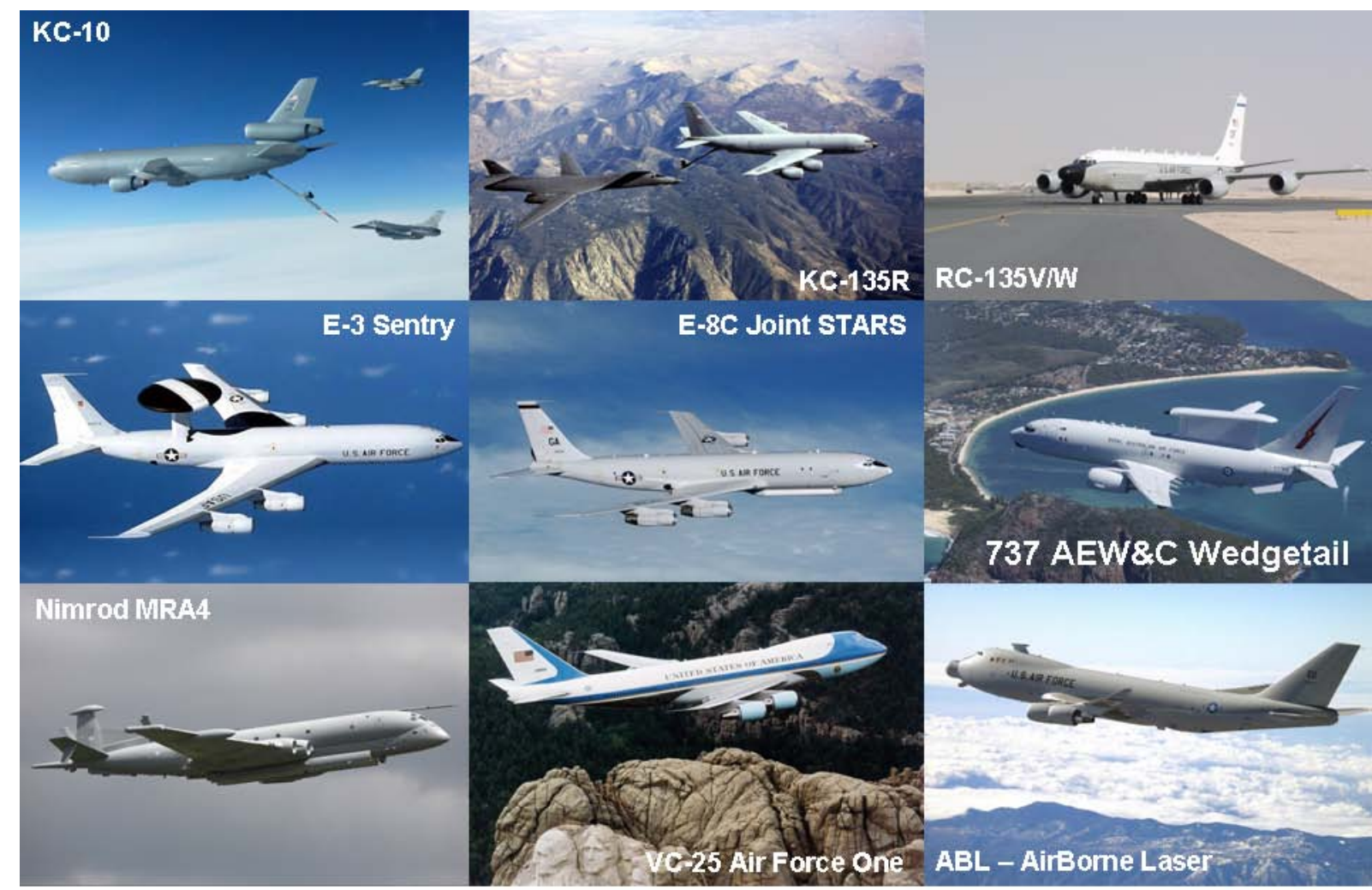

Figure 1: Examples of Military Derivative Aircraft ${ }^{4}$

The P-8A Poseidon program has focused on modifications to existing military or commercial airframes mainly due to limited development budget, rapidly diminishing P-3 airframe life, and the need to field replacement aircraft in the 2012-2014 timeframe. The systems engineering strategy has emphasized developing, refining, managing, and translating affordable, technically achievable requirements as a primary objective. Establishing systems engineering processes that seamlessly link requirements from the Defense Planning Guidance to performance specifications and collaborating with industry partners to mature system requirements are hallmarks of the program philosophy ${ }^{5}$.

The program includes five development test aircraft, three of which are flight test aircraft. Specifically: 1) the T1 airworthiness/envelope expansion test article, intended for verifying the flying qualities, performance, loads and in-flight refueling; 2) the T2 primary mission system flight test article, intended for verifying the performance of all sensors; 3) the T3 mission system and weapon certification aircraft, intended for ground stores and separation testing; plus 4) the S1 static test article, intended to support the envelope expansion for T1; and 5) the S2 fatigue test article, intended to test the airframe to two fatigue lifetimes. The program also entails three production representative test aircraft T4, T5, and T6 ${ }^{6}$. Figure 2 is a snapshot of the first flight of the T2 aircraft.

The P-8A Poseidon's key features entail ${ }^{7}$ : 
- Open Mission System Architecture: Reconfigurable and expandable system facilitating easier and more affordable upgrades.

- Sensors: Active multi-static and passive acoustic sensor system, inverse synthetic aperture/synthetic aperture radar, new electronic support measures system, new electrooptical/infrared sensor, and magnetic anomaly detector.

- Nine-person crew: Dual-pilot cockpit, five mission crew plus relief pilot and in-flight technician. Workstations with universal multi-function displays, ready accommodation for additional workstation, and workload sharing.

- Lethality: Internal weapons bay, four wing pylons, and two centerline hard points with digital stores management allowing for carriage of joint missiles, torpedoes, and mines.

- Search stores: Rotary reloadable sonobuoy launchers.

- Net Ready: Link-16, Internet Protocol, Common Data Link (CDL), and FORCEnet.

- Performance based support/logistics: With availability as a key performance parameter.

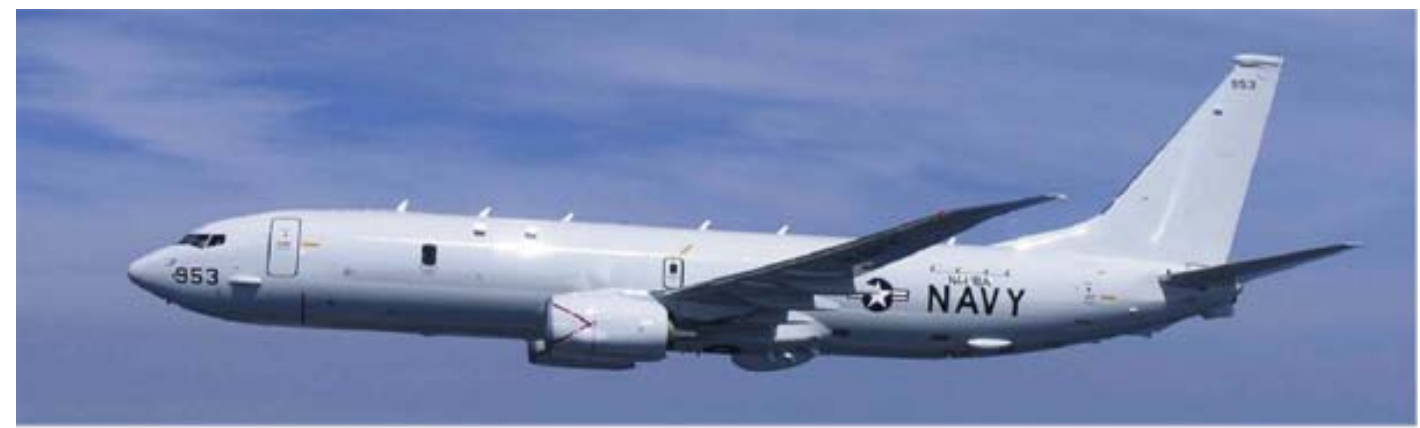

Figure 2: First Flight of the T2 Aircraft ${ }^{8,6}$

\section{Acquisition Strategy ${ }^{9}$}

The P-8A Poseidon Program is structured on an evolutionary systems replacement approach that aligns the processes employed for requirements definition, acquisition strategy, and system development into a dynamic and flexible means to attain the strategic vision for tomorrow's naval forces.

The method used for P-8A Poseidon requirements definition has capitalized on an iterative process with industry and the fleet. It promotes evolutionary growth in capabilities while providing a transformational product to the users. Matched with this requirements definition process is the evolutionary acquisition strategy. For the P-8A Poseidon, this strategy focuses on delivering the first increment in capability to the users in the earliest, most cost-efficient manner to address the Navy's inventory issue. The program will concurrently pursue increases in system capabilities through a spiral development process that allows the system to keep pace with emerging technologies and the strategic requirements of both the Navy and Joint forces.

The spiral development process will address capabilities in well-defined blocks of functionality. In Block 1, the P-8A Poseidon Program will focus its resources on the development of an innovative systems architecture that will promote system growth and flexibility. This will be accomplished by basing the design of the mission system on an open systems architecture that will allow system evolution through the spiral development process and provide increased capabilities through future incremental block upgrades. The results will be the rapid delivery of a transformational system to the Fleet via the initial Block 1 capability ${ }^{5}$.

In implementing the acquisition strategy the U.S. Navy adopted a four-phase approach to the acquisition of the P-8A Poseidon. The four phases are: 


\section{Phase 1: Concept Exploration}

This phase is highlighted by the following milestones:

o The analysis of alternatives (AoA) study that was completed in November 2001

o Acquisition Documentation to support the component advanced development (CAD) decision review

0 Source selection for CAD phase

o Study of UAV in Broad Area Maritime Surveillance (BAMS) roles

In 1998 and 1999 the Navy conducted a Mission Area Analysis after recognizing the need to field a follow-on system to the P-3. This analysis was conducted using Strategy-to-Task "Quality-Function-Deployment” methodology and a Short-falls Analysis, respectively. A Technical and Economic Feasibility Analysis of several potential aircraft alternatives was conducted as well. This pre-concept exploration work supported the development of a Broad Area Maritime Surveillance (BAMS) and Littoral Armed Intelligence Surveillance and Reconnaissance Mission Need Statement that was validated and approved by the Joint Requirements Oversight Council (JROC) on 29 February 2000. This enabled a Milestone 0 decision and entry into the concept exploration phase. The current DODI 5000.2, issued on 12 May 2003, now defines Milestone A as entry into the analogous technology development phase $^{5}$. Concept exploration entailed the Analysis of Alternatives (AoA) and Industry Concept Studies.

\section{Analysis of Alternatives (AoA)}

The Analysis of Alternatives (AoA) study was executed by the Center for Naval Analyses (CNA). It examined a broad range of potential solutions including manned and unmanned aerial vehicles (UAVs) and satellites. Viable options identified from Phase I included a newproduction P-3 derivative, a medium-sized commercial derivative based on the Boeing 737 or Airbus A320, a large-sized commercial derivative based on the Boeing 757 or Airbus A321, and a military derivative based on the Nimrod MRA4 ${ }^{5}$. The AoA concluded that:

o Manned aircraft is identified as an element of the Multi Mission Maritime system

o Viable manned aircraft alternatives include:

- Medium size commercial derivatives (737, A320)

- Military derivatives (New P-3, Nimrod MRA4)

o Unmanned aircraft have a role as an adjunct capability

\section{Industry Concept Studies}

To support the Analysis of Alternatives (AoA), the U.S. Navy PMA290 awarded the industry concept studies to:

o Lockheed Martin to study the P-3 derivative (Orion 21)

o Raytheon to study the P-3 derivative (Procyon)

o Boeing to study the 737 derivative

o Northrop Grumman to study the Global Hawk Adjunct UAV

The AoA and industry concept studies further refined the requirements boundaries and served as a basis for developing an Initial Requirements Document (IRD). The Program Office and industry have collaboratively refined the requirements and top-level specifications through the IRD and Draft Performance Based Specification (PBS) during the component advanced development (CAD) phase. This collaboration was crucial to ensure that industry fully 
understands the Navy's expectations and that the Navy fully appreciates the cost and schedule impacts of the requirements on each specific industry alternative ${ }^{5}$. This requirements maturation process is represented in Figure 3.

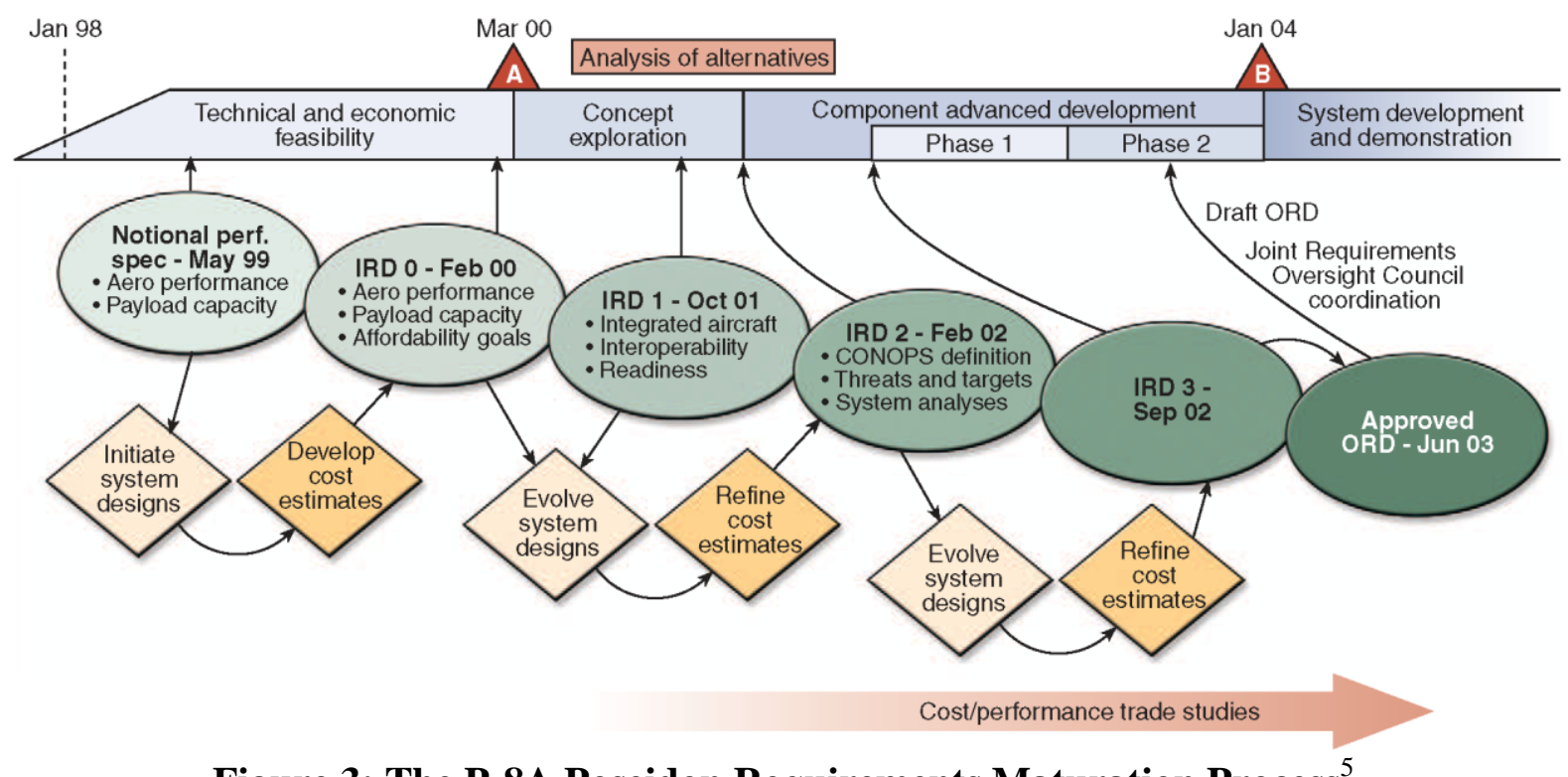

Figure 3: The P-8A Poseidon Requirements Maturation Process ${ }^{5}$

On 11 January 2001, and following the report of initial AoA findings, the Secretary of the Navy (SECNAV) sent a memorandum to the Deputy Secretary of Defense stating that:

o Maritime Patrol and Reconnaissance (MPR) aircraft provide critical antisubmarine warfare and intelligence, surveillance, and reconnaissance capability

o The P-8A Poseidon program plan provides a dynamic and viable solution for recapitalizing the P-3C Orion and EP-3 Aries force

o Initial Operational Capability (IOC) will be achieved in the 2010-2013 timeframe

o P-3C Orion Aircraft Improvement Program (AIP) will provide evolutionary path for P-8A Poseidon sensors

\section{Phase 2: Component Advanced Development (CAD)}

This phase is highlighted by the following milestones:

o Define the P-8A Poseidon system architecture for each alternative concept

o Identify the total ownership cost (TOC) of the P-8A Poseidon alternative concepts

o Refine system requirements and support the operational requirement document (ORD) validation process

o UAV requirements development

The detailed milestones of the CAD phase are illustrated in Figure 4. PMA-290, the P-8A Poseidon Program Office, tasked Johns Hopkins Applied Physics Lab (APL) with performing an assessment of the capability of the legacy P-3C Orion aircraft sensor subsystems meant for the baseline P-8A. The P-8A Poseidon Platform Performance Assessment was conducted over a yearlong period commencing in October 2001. The purpose of this assessment was twofold: (1) to provide an analytical basis for deriving critical system characteristics and key performance parameters for inclusion in the P-8A Poseidon Operational Requirements Document (ORD), and (2) to provide a framework for conducting trade-offs among design and technology options during the P-8A Poseidon Component Advanced Development phase. 
The task involved developing 11 operational situations (OPSITs) and 41 tactical situations (TACSITs) for use in conducting operational analyses in support of the P-8A Poseidon Program in general as well as providing the basis for the platform assessment. Example missions focused on antisubmarine and surface warfare in addition to mining and maritime surveillance.

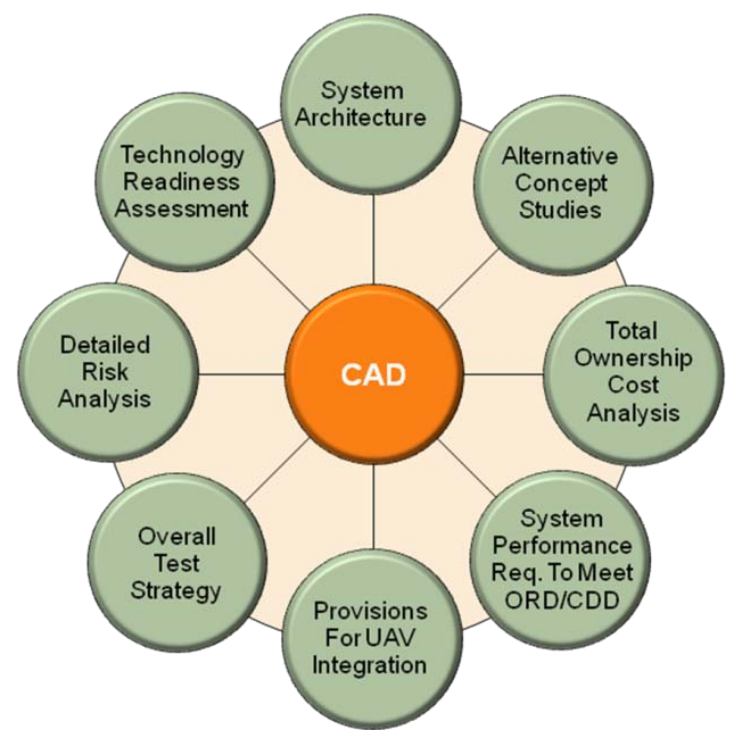

Figure 4: Detailed Milestones of the CAD Phase ${ }^{10}$

The OPSITs were derived from various existing DoD-approved scenarios and covered the spectrum of warfare from pre-hostilities to a major theater war in a variety of geographic and environmental conditions. These snapshots were designed to examine specific mission performance parameters and requirements in typical missions involving a reasonable threat and other joint assets ${ }^{3}$.

The operational context consists of OPSITs that contain the Mission of the P-8A ${ }^{11}$. Specifically:

o Friendly and threat assets

0 Threat characterizations and order of battle (OOB)

o P-8A basing

o Airfield weather data

o Route-of-flight information

o Physical environment characterizations

The OPSITs and TACSITs were developed within the context of the P-8A Poseidon Design Reference Mission (DRM.) A Design Reference Mission (DRM) defines the specific projected threat and operating environment baseline for a given force element, which may range from a single-purpose weapon system to a multi-mission platform to a multi-system, multi-platform system of systems. The P-8A Poseidon DRM provides a notional description of deployed operations for the future P-8A. It is primarily an engineering/design tool to support systems engineering activities by identifying significant design-driving operational elements and characterizing them to the level of detail necessary to assess design impact. The DRM is intentionally modular to allow the U.S. Navy to tailor or modify the scenario and its components over time in order to update aircraft operating and warfighting requirements and prospective solutions ${ }^{11}$. 
The DRM also serves as a framework to evaluate the reliability, availability, and maintainability (RAM) characteristics of the P-8A Poseidon design as it evolves and to demonstrate the potential to meet the operational availability thresholds in proposal analyses and presentations. Figure 5 illustrates the Common Systems Engineering Process with the DRM as a key element of the systems operating environment definition, which establishes the foundation for systems engineering trade studies and specification development. The development of the P-8A Poseidon DRM is illustrated in Figure 6.

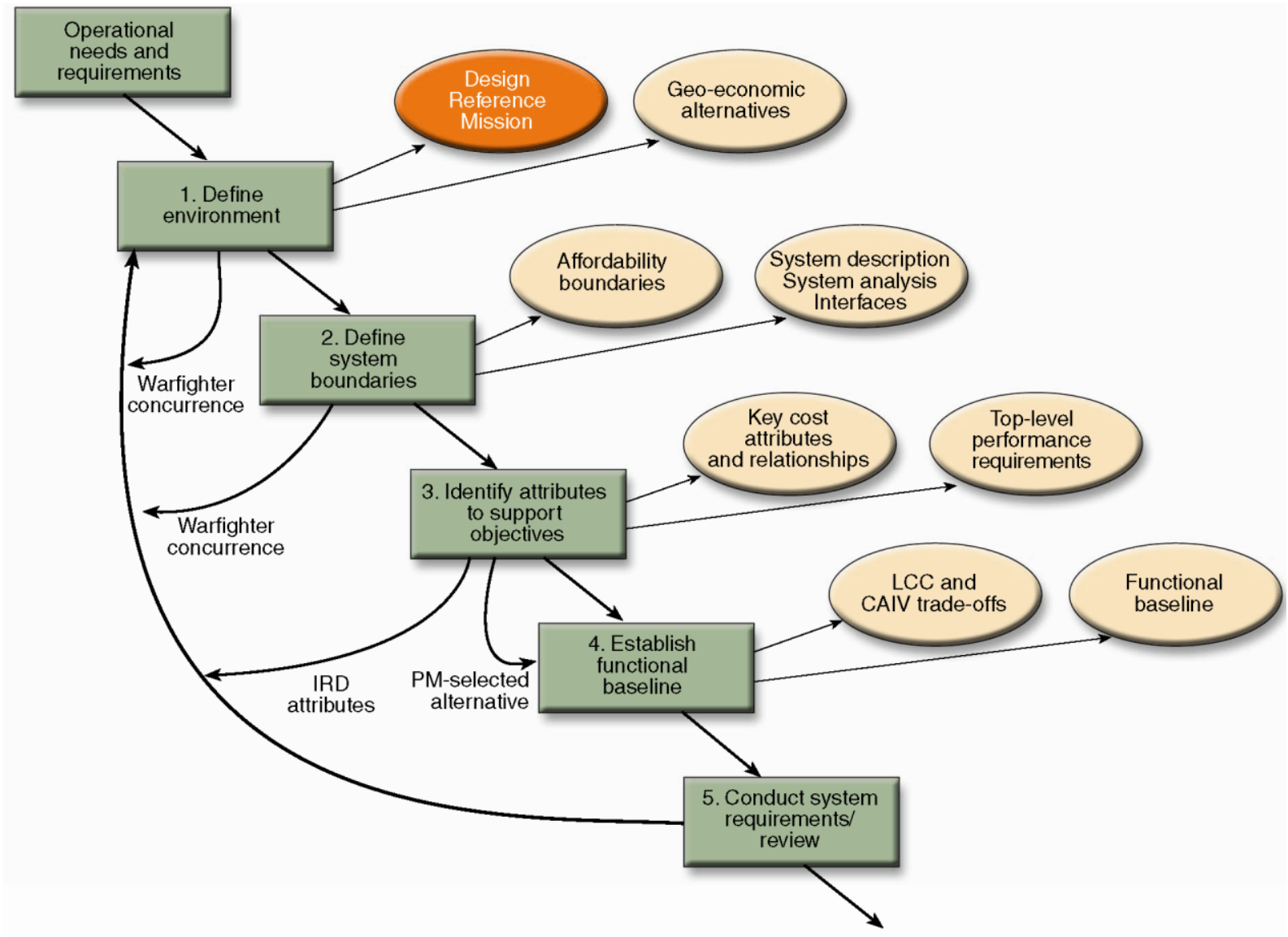

Figure 5: The Common Systems Engineering Process ${ }^{11}$

(a) IRD

\begin{tabular}{|l|}
\hline MMA IRD \\
performance parameters \\
Mission prep time \\
Payload \\
Crew size/loading \\
Take-off weight \\
Take-off distance \\
Altitude \\
Speed \\
Distance \\
Time on station \\
Internal/external loads \\
Survivability \\
Vulnerability \\
Surveillance \\
Reconnaissance \\
Situational awareness \\
Connectivity \\
Supportability \\
Lethality
\end{tabular}

(b) Matrix Diagram

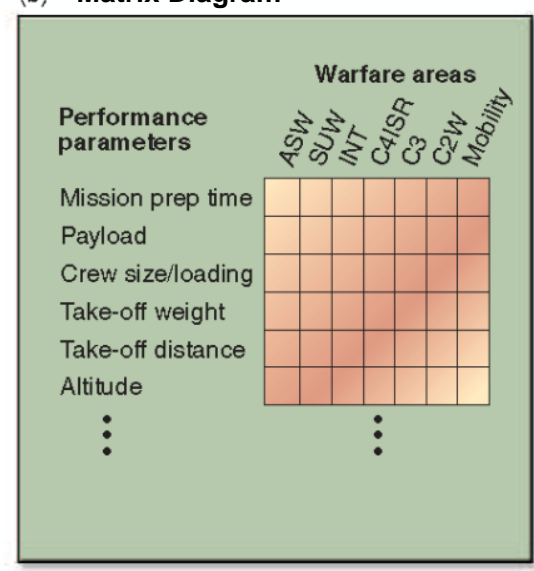

(c) OPSITS/TACSITS

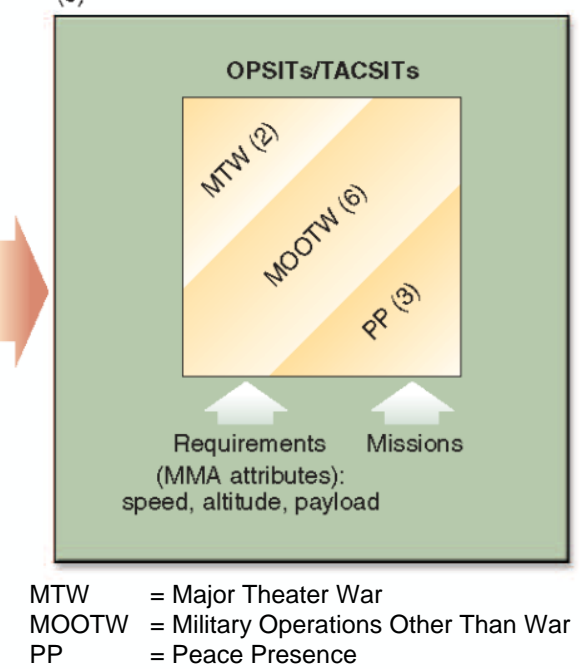

Figure 6: Development of the P-8A Poseidon DRM ${ }^{11}$ 


\section{Phase 3:System Development \& Demonstration (SDD)}

This phase is highlighted by selecting a single prime contractor for the P-8A Poseidon system to achieve the following milestones:

o Develop detailed system and subsystem designs for the P-8A

o Develop systems integration labs (SIL) and build developmental test aircraft

o Conduct integrated team development and integration tests

o Develop and/or acquire Integrated Logistics Support (ILS) and training systems to support developmental and initial operational testing

\section{Phase 4:Production and Deployment (P\&D)}

This phase is highlighted by the following milestones:

o Begin low rate initial production (LRIP)

o Complete the operational evaluation (OPEVAL)

o Target the full rate production stage (FRP) decision to support initial operational capability by the year 2013

o Continue the technology refresh in successive blocks

Mission systems will feature a high degree of commonality between P-8A Poseidon mission system variants by sharing a similar air vehicle configuration and an open system architecture that will ensure evolutionary mission system capability. This is achieved through guaranteeing that:

o Initial production blocks must provide an overall mission system capability no less effective than the P-3C Orion Update III anti-surface warfare improvement program (AIP) and EP-3E Aries joint signal intelligence avionics family modification program (JMOD) I baselines

o Open system architecture should ensure command, control, communications, computers, and intelligence (C4I) interoperability and supportability throughout the P-8A Poseidon life cycle

Logistic support will maximize P-8A Poseidon Fleet Squadron support and achieve maximum aircraft availability at the lowest operational and support (O\&S) costs through ${ }^{12}$ :

o Innovative logistic solutions entailing commercial support concepts to be evaluated during the component advanced development (CAD) and establishing partnering and/or teaming arrangements

o Operational and support (O\&S) cost reductions through the minimization of the operational and support (O\&S) costs in relation to the P-8A Poseidon total ownership cost (TOC). This is achieved through logistics footprint reduction, organic manpower reduction, competitive base for depot level maintenance and component repair, and increased component reliability.

\section{Design and Testing Strategy}

Though the P-8A Poseidon is a derivative of the highly successful and reliable NextGeneration 737, having the fuselage of a 737-800 and the wings of a 737-900, the P-8A aircraft has been refined through wind-tunnel testing and is expected to comfortably meet requirements with room for growth ${ }^{13}$. 
Design and Testing, as illustrated in Figure 7, are two major process events affecting the Structural Life of the P-8A Poseidon. The 737NG is the second commercial airliner, after the Boeing 777, to be digitally designed and built, offering the promise of a state-off-the-art production line. The design drawings were generated using the virtual design capabilities of Dassault Systems CATIA CADCAM solution. CATIA is a pioneer brand and the World's leading solution for product design and innovation.

The baseline P-8A Poseidon has changed, and evolved, relative to the 737-800ERX. These changes entail: a) major structural design changes, Figure 8; b) the increase in gross take-off weight; c) the increase in external loads; d) the difference in flight mission profiles; and e) the difference in operational environments. To assess the impact of these changes on the structural loads a full scale finite element model that entails the entire aircraft was developed. This model was used to compute the internal structural loads that are induced by the aerodynamic, aeroelastic, thermal, or ground external loads of any flight mission.

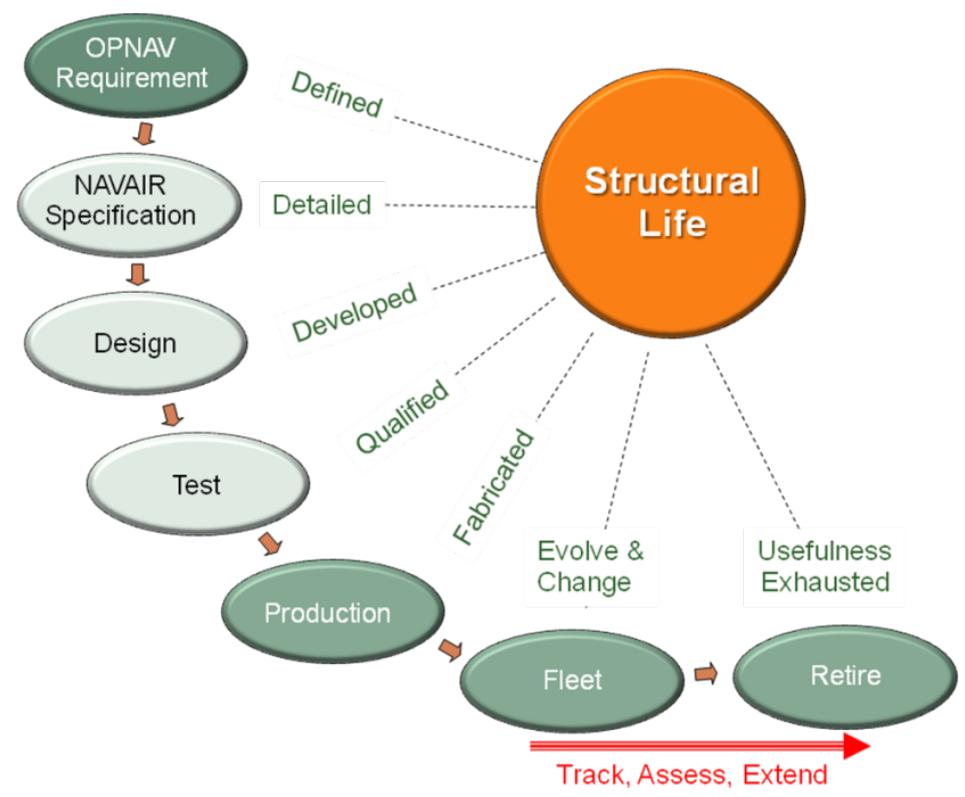

Figure 7: Process Events influencing Structural Life of Aircraft ${ }^{14}$

These changes dictated that the entire structure be analyzed under static loads to ensure that it will demonstrate Non Detrimental Deformation (NDD) or yielding at NDD loads and will not fail at ultimate loads. The NDD loads were designed to be higher than the limit loads and lower than the ultimate loads.

The structure was also analyzed under spectrum fatigue loading that simulates the flight missions fatigue loads for the entire service life of the aircraft. These analyses ensured that: a) a Safe Life part has fatigue life that equals or exceeds the Design Service Objective (DSO); b) a Damage Tolerance Part will not develop a critical crack during the DSO or it is inspected for crack initiation and propagation at an inspection frequency that would not allow a critical crack to go undetected. As illustrated in Figure 9, Fatigue Life is a major determinant of the Operational Service Life (OSL) of the aircraft.

The P-8A static test program entails testing several key structures to NDD and ultimate load levels. In addition, a full-scale static test of the S1 aircraft will be performed to same load levels. The fatigue test program entails testing the S2 aircraft to two lifetimes under spectrum fatigue loads that simulate the flight missions fatigue loads for the entire service life. This test program makes the P-8A Poseidon the second 737 NG derivate, after the 737-700, to undergo full scale static and fatigue testing. 


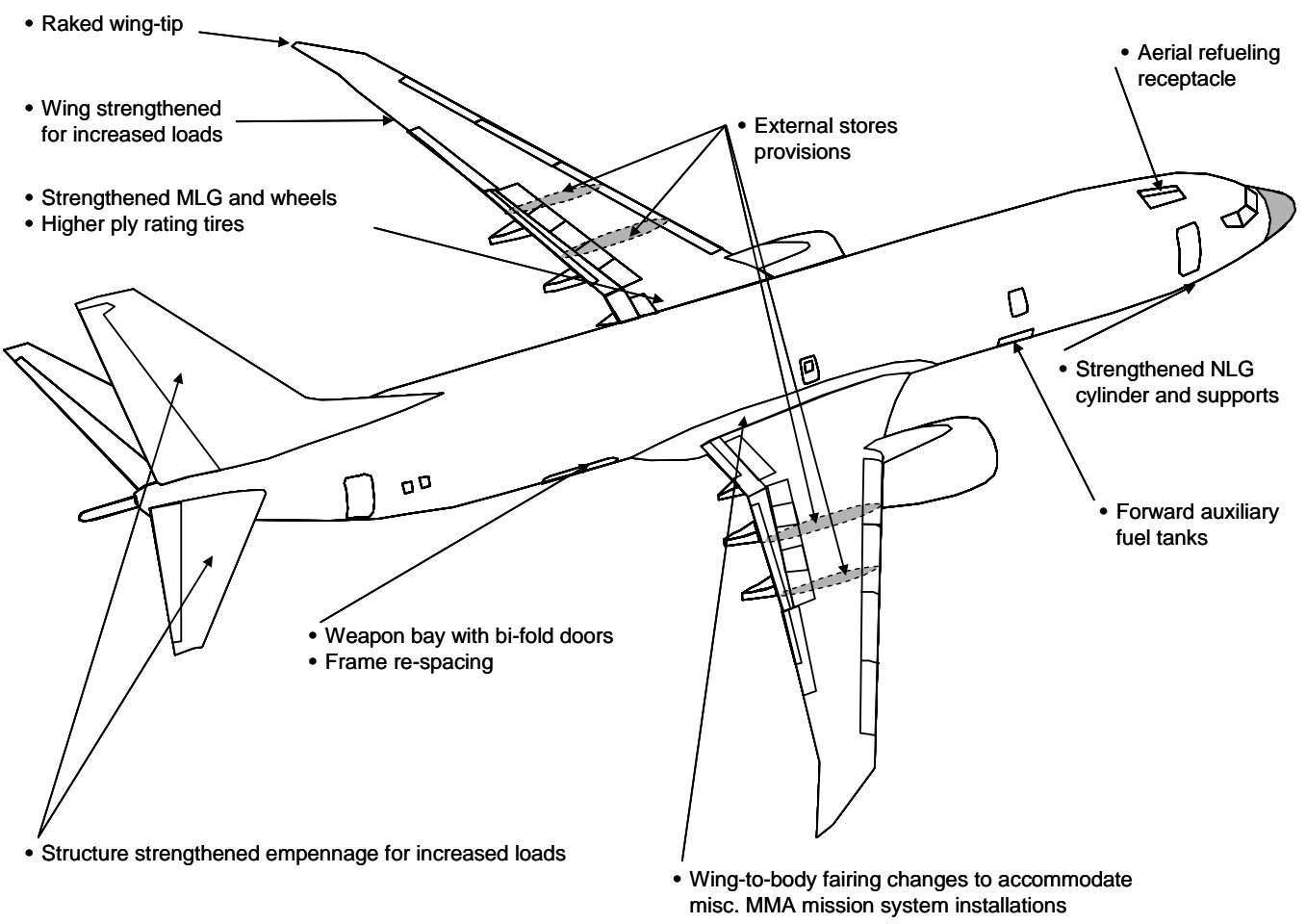

Figure 8: P-8A Major Structural Design Changes

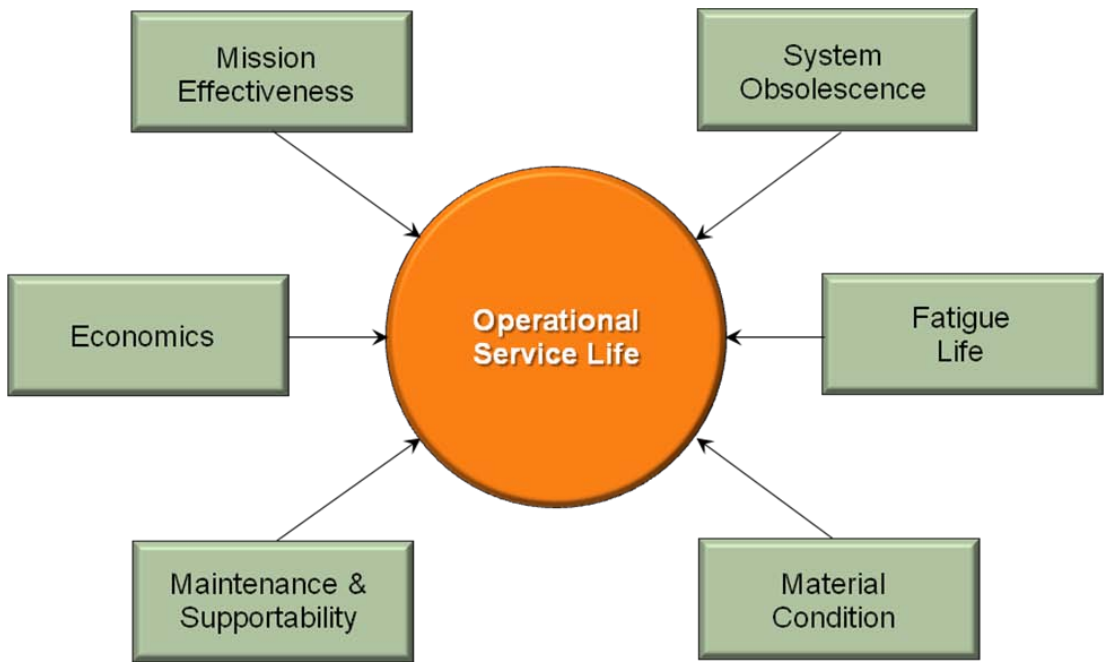

Figure 9: Operational Service Life (OSL) ${ }^{15}$

Flight tests by Boeing will entail: a) verifying the flying qualities, performance, loads and inflight refueling using the T1 aircraft; b) verifying the performance of all sensors using the T2 aircraft; c) ground stores and separation testing using the T3 aircraft. Flight tests by the U.S. Navy entails, in addition the above three test articles, three production representative test aircraft T4, T5, and T6.

\section{Manufacture Strategy}

Modifications to the baseline commercial aircraft are incorporated into the aircraft in-line. In the past, commercial aircraft were sent to modification centers where they were taken apart and rebuilt to meet military specifications. The P-8A Poseidon is Boeing's first military derivative aircraft to incorporate structural modifications to the aircraft as it moves through the commercial line ${ }^{1}$. This is illustrated in Figure 10. 
The quality and performance acceptance flight testing of the aircraft will be conducted from Renton Field and final installations and checkout of the mission system and special flight test instrumentation will be conducted at the Boeing Field. The aircraft will then ferry to Naval Air Station at Patuxent River, Maryland, for flight test.

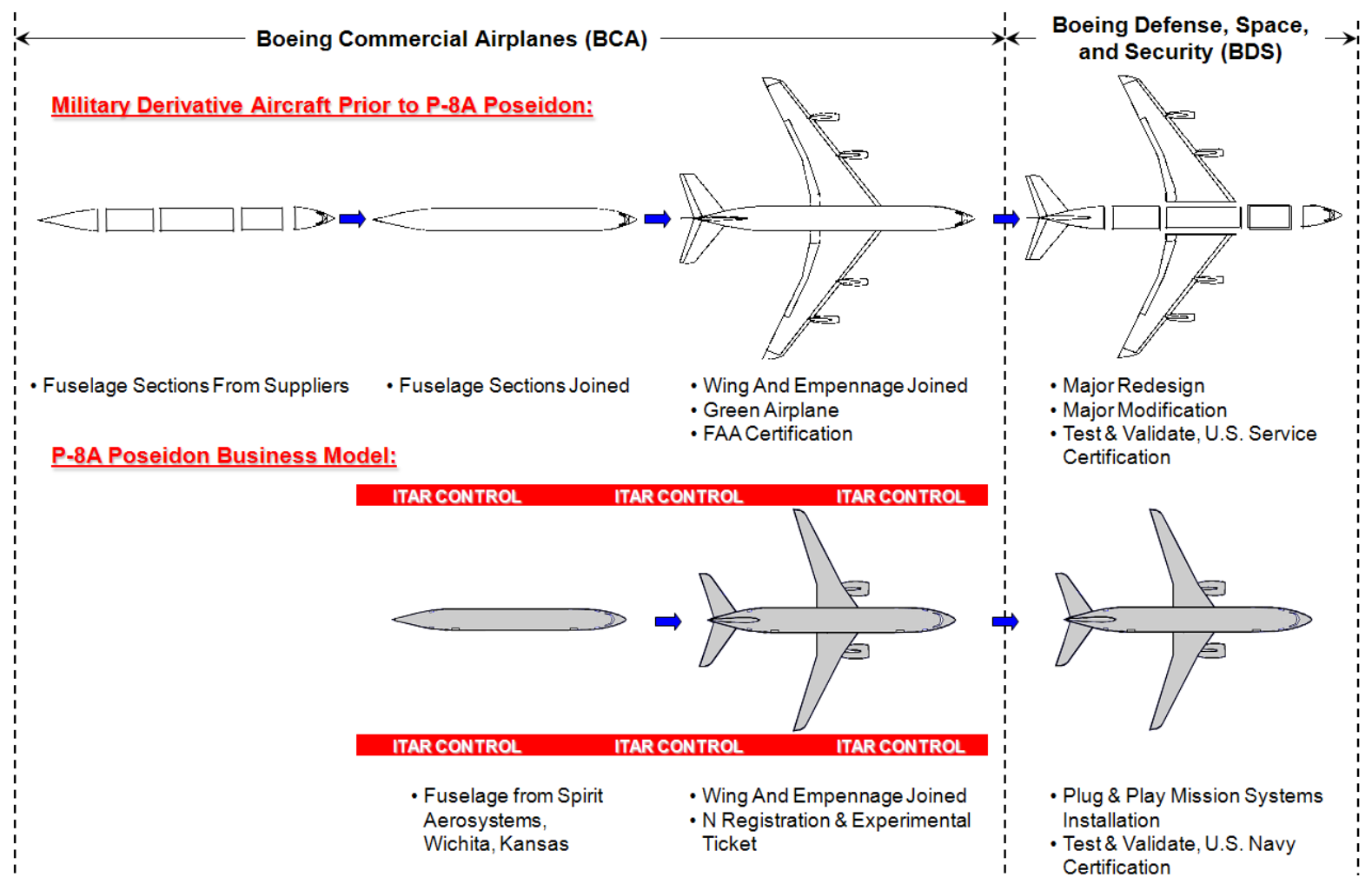

Figure 10: The New Business Model Adopted for the Manufacture of the P-8A Poseidon

\section{Integration Strategy}

In addition to being the prime contractor for the P-8A Poseidon, developing the key avionics hardware including the mission computers and acoustic processor, manufacturing the wings and empennage, and assembling the airframe at its Renton, Washington facility, Boeing will act as a system-of-systems integrator for the P-8A Poseidon. Boeing and its industry partners provide unrivaled expertise in both large-scale systems integration and network centric operations, plus unquestioned leadership in developing and customizing military and commercial products for maritime forces ${ }^{16}$. The list of partners entails:

CFM International is a 50/50 joint company of Snecma Moteurs and General Electric Company. It provides the CFM56-7 engines that will power the P-8A. The CFM56-7 is one of the world's most reliable engines.

Northrop Grumman Electronic Systems sector will provide the directional infrared countermeasures system and the electronic support measures system. The Mission Systems sector will develop data links for P-8A. The company's Integrated Systems sector will support the mission planning effort.

Raytheon will provide an upgraded APS-137 Maritime Surveillance Radar and Signals Intelligence (SIGINT) solutions. Raytheon is also offering its revolutionary GPS AntiJam, Integrated Friend or Foe, and Towed Decoy Self-Protection suites, and the aircraft's Broadcast Info System (BIS) and secure UHF Satcom capability. 
Smiths Aerospace will supply both the Flight Management and Stores Management systems on the P-8A. The Flight Management System provides a truly integrated open architecture that is Communications, Navigation, Surveillance (CNS)/Air Traffic Management (ATM) compatible along with an inherent growth path for upgrades. The Stores Management System provides a comprehensive system for the electronic control of integrated weapons management.

$>$ Spirit AeroSystems will build the 737 aircraft's fuselage and airframe tail sections and struts in Wichita, Kansas.

Since the P-8A Poseidon is a collection of nested systems and subsystems operating in unison, its operational environment will be a complex and adaptive blend of sensors, shooters, Command and Control assets and data links. This fact dictates conducting a number of integration analyses and tests including the Top-Down Function Analysis (TDFA) and the Intrasystem Electromagnetic Compatibility (EMC) tests.

A Top-Down Function Analysis (TDFA) was conducted within the P-8A Poseidon program. TDFA is a family of systematic analyses that decompose the mission of an emerging system in a manner that links hardware, software, and human performance requirements to the intended mission. The primary purpose of this TDFA was to determine specific areas on which to focus training development. The data within this analysis also have value to support human engineering decisions on what specific tasks and functions may require design support as well, e.g. decision aids, display and control, automation, etc. These data could support decision making related to manpower and the allocation of tasks/functions to operators and maintainers. The P-8A Poseidon TDFA process is an excellent example of a large-scale Navy program implementing analysis techniques that provide opportunities for dialog between the Systems Engineering (SE) and Human Systems Integration (HIS) disciplines ${ }^{17}$.

Intrasystem Electromagnetic Compatibility (EMC) tests will be concentrated on the integrated P-8A Poseidon mission systems. These tests will be conducted in the Advanced Systems Integration Laboratory (ASIL) at Kent, Washington. To properly test the effectiveness of such advanced weapons systems, the entire aircraft must be stimulated as it would be in an actual mission environment. Stimulating only a few mission systems leaves the remainder of the aircraft's integrated systems in a static state and represents unrealistic mission profiles. Stimulating only a portion of the mission systems also allows little chance of identifying adverse electromagnetic interactions ${ }^{18}$.

\section{Interoperability Strategy}

In his 2005 Annual Report to the President and Congress, Donald H. Rumsfeld, then Secretary of Defense wrote "One trend is clear: the Department's transformation will be shaped by the emerging realities of the information age. Just as the move from the industrial age to the information age is changing the relative value of the sources of economic wealth; it is also altering the relative value of capabilities, assets, and skills that underwrite national security. Processes and organizations that cannot adapt to a networked, interoperable environment will not provide the knowledge, speed, precision, and agility we will need in the future.

More important, old ways of thinking will not foster the human skills demanded by our emerging security environment. Intellectual agility, adaptability, and the capacity to act in the midst of dynamic complexity and uncertainty have increased importance in informationage warfare. 
Integral to the Department's transformation, are the initiatives being conducted by each of the Military Departments. These coordinated efforts are fundamentally changing processes and products by enhancing efficiency, joint interoperability, and warfighting effectiveness. These initiatives, furthermore, will make Net-Centric Operations/Warfare an operational reality by integrating weapons, sensors, command/control, platforms, and warriors into a secure networked, distributed joint combat force as part of the DoD Global Information Grid.”

He stated this when discussing Define Skills and Competencies for the Future ${ }^{19}$. A manifestation of this statement is the complex interoperability environment in which the P-8A Poseidon will operate, Figure 11.

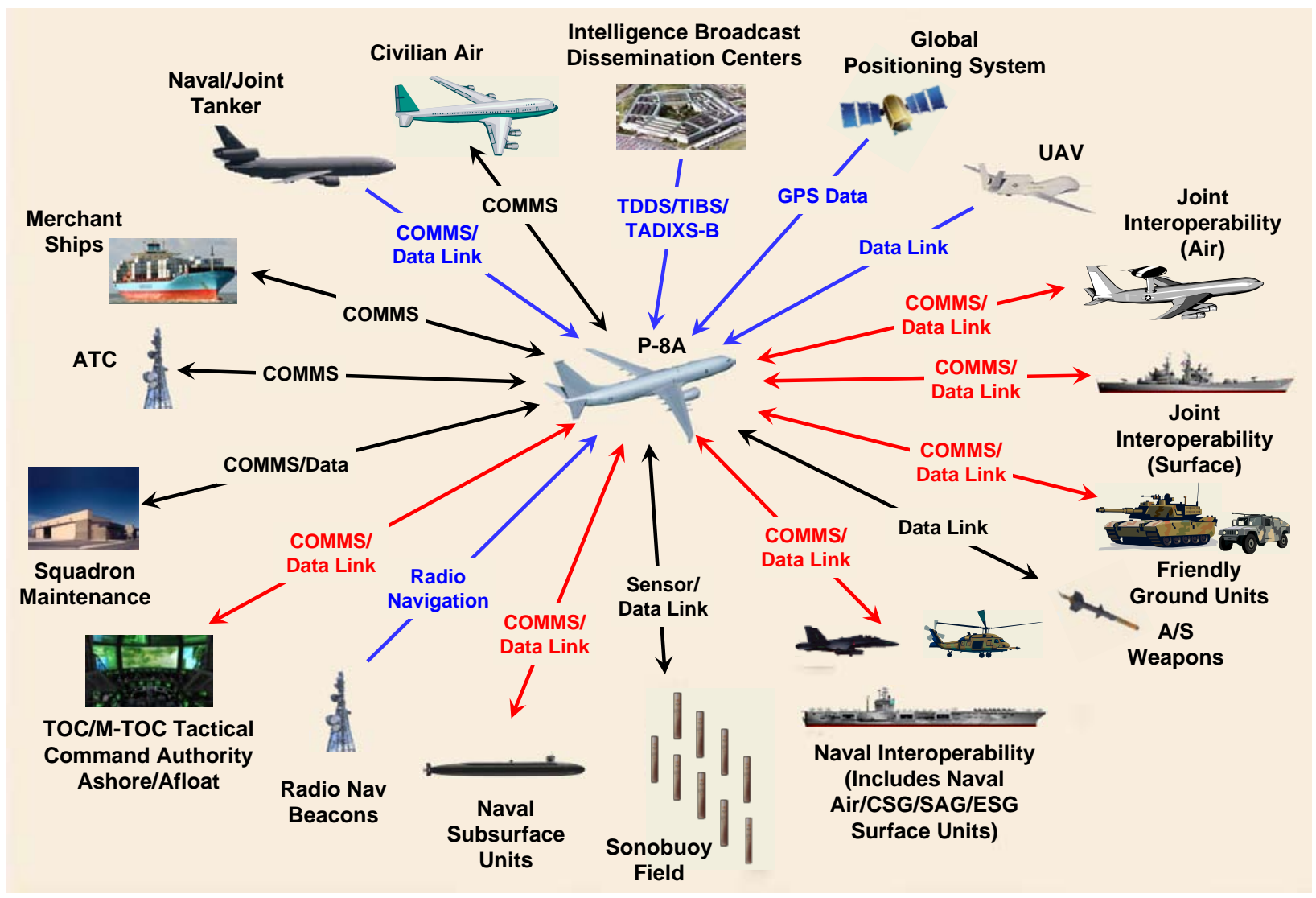

Figure 11: The Interoperability Environment of the P-8A Poseidon ${ }^{20}$

Though the U.S. Navy program manager for the P-8A Poseidon program stated that the contractor would be providing an airborne "truck" to replace the aged P-3 airframe while retaining the mission equipment, Boeing Defense, Space \& Security (BDS), the P-8A Poseidon prime contractor, openly applauded the opportunity to insert common mission modules from other programs, taking advantage of newer technology and an open systems architecture to support modularity, upgradability, interoperability, and lower total cost of ownership from an acquisition support and training perspective ${ }^{21}$.

\section{Survivability Strategy}

As the P-8A Poseidon force operates more in littoral areas, there will be an increased likelihood that it will enter the engagement envelope of threat systems. Pop-up threats justify the need for the P-8A Poseidon force to carry some basic countermeasures equipment to avoid or survive an engagement. The radar and IR signatures of these types of airframes are quite 
large, and the aircraft are relatively slow. Without survivability enhancements, such aircraft would be quite susceptible to land-based, air-to-air, and ship-based radar and IR missile threats and to anti-aircraft artillery (AAA) and ship-based guns. Figure 12 illustrates the elements of survivability of an air vehicle ${ }^{22}$.

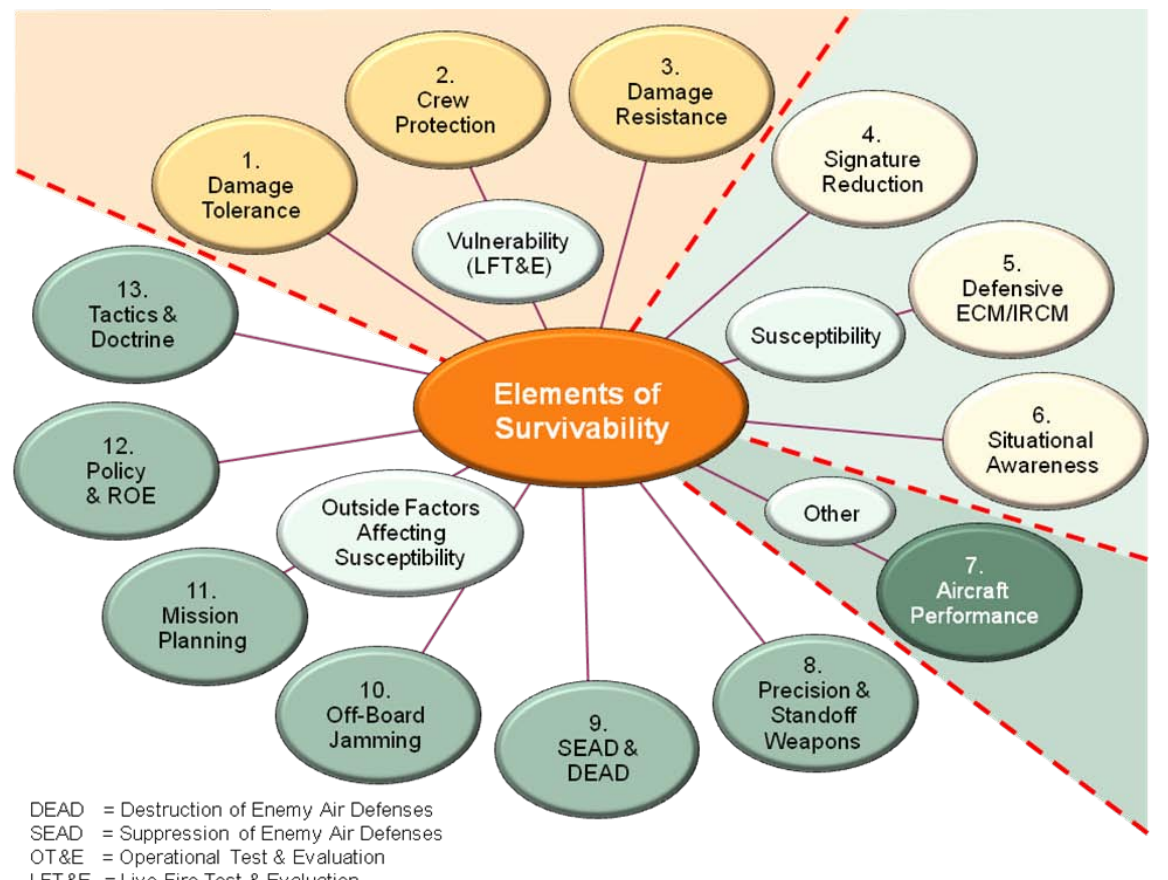

Figure 12: Elements of Survivability ${ }^{22}$

The Navy's P-8A Poseidon program has generated data supporting the hypothesis that reduction in fuel-related vulnerabilities can have a large influence on the survivability of a commercial derivative design. Other studies concluded that numerous enhancements were needed, including a missile warning system, a countermeasures dispenser, a radio-frequency (RF) jammer, fuel tank protection, dry bay fire suppression, and flight control system hardening. The P-8A Poseidon program has evaluated many technologies to address fuel tank fire suppression and dry bay protection with the objective of achieving the most effective capabilities while minimizing cost, weight and reliability penalties ${ }^{2}$.

With fuel tank fire suppression, dry bay protection, and countermeasures to deal with both radar-guided and IR-guided threats the P-8A Poseidon has a far greater chance of surviving and being able to complete its missions ${ }^{23,24,25}$.

\section{Acronyms}

$\begin{array}{ll}\text { A/S } & \text { Anti-Submarine } \\ \text { AAA } & \text { Anti-Aircraft Artillery } \\ \text { AIP } & \text { Aircraft Improvement Program } \\ \text { AoA } & \text { Analysis of Alternatives } \\ \text { APL } & \text { Johns Hopkins University Applied Physics Lab } \\ \text { ASIL } & \text { Advanced Systems Integration Laboratory } \\ \text { ASW } & \text { Anti-Submarine Warfare } \\ \text { ATC } & \text { Air Traffic Control } \\ \text { ATM } & \text { Air Traffic Management } \\ \text { BAMS } & \text { Broad Area Maritime Surveillance }\end{array}$




\begin{tabular}{|c|c|}
\hline BDS & Boeing Defense, Space \& Security \\
\hline $\mathrm{C} 2 \mathrm{~W}$ & Command and Control Warfare \\
\hline C3 & Command, Control and Communications \\
\hline C4I & Command, Control, Communications, Computers and Intelligence \\
\hline C4ISR & $\begin{array}{l}\text { Command, Control, Communication, Computers, Intelligence, Surveillance } \\
\text { and Reconnaissance }\end{array}$ \\
\hline CAD & Component Advanced Development \\
\hline CADCAM & Computer Aided Design Computer Aided Manufacture \\
\hline CAIV & Cost as an Independent Variable \\
\hline CAN & Center for Naval Analyses \\
\hline CATIA & Computer Aided Three Dimensional Interactive Application, Dassault Systems \\
\hline CDD & Capability Development Document \\
\hline CDL & Common Data Link \\
\hline CNS & Communications, Navigation, Surveillance \\
\hline CSG & Carrier Strike Group \\
\hline DEAD & Destruction of Enemy Air Defenses \\
\hline DRM & Design Reference Mission \\
\hline DSO & Design Service Objective \\
\hline ECM & Electronic Counter Measure \\
\hline EMC & Intrasystem Electromagnetic Compatibility \\
\hline ESG & Expeditionary Strike Group \\
\hline FRP & Full Rate Production \\
\hline ILS & Integrated Logistics Support \\
\hline INT & Interrupt \\
\hline IOC & Initial Operational Capability \\
\hline IRCM & Infrared Countermeasure \\
\hline IRD & Initial Requirements Document \\
\hline ISR & Intelligence, Surveillance, and Reconnaissance \\
\hline JMOD & Joint Signal Intelligence Avionics Family Modification Program \\
\hline JROC & Joint Requirements Oversight Council \\
\hline LCC & Life Cycle Cost \\
\hline LFT\&E & Live Fire Test and Evaluation \\
\hline LRIP & Low Rate Initial Production \\
\hline MOAC & Modular Air Operations Center \\
\hline MOOTW & Military Operations Other Than War \\
\hline MPR & Maritime Patrol and Reconnaissance \\
\hline MTW & Major Theater War \\
\hline NAVAIR & Naval Air Systems Command \\
\hline NDD & Non Detrimental Deformation \\
\hline NLG & Nose Landing Gear \\
\hline O\&S & Operations and Support \\
\hline OOB & Order Of Battle \\
\hline OPEVAL & Operational Evaluation \\
\hline OPNAV & Office of the Chief of Naval Operations \\
\hline OPSIT & Operational Situation \\
\hline ORD & Operational Requirement Document \\
\hline OSL & Operational Service Life \\
\hline OT\&E & Operational Test and Evaluation \\
\hline$P \& D$ & Production and Deployment \\
\hline PBS & Performance Based Specification \\
\hline PP & Peace Presence \\
\hline
\end{tabular}




$\begin{array}{ll}\text { RAM } & \text { reliability, Availability, And Maintainability } \\ \text { RF } & \text { Radio Frequency } \\ \text { ROE } & \text { Rules Of Engagement } \\ \text { SAG } & \text { Surface Action Group } \\ \text { SDD } & \text { System Development \& Demonstration } \\ \text { SEAD } & \text { Suppression of Enemy Air Defense } \\ \text { SIGINT } & \text { Signals Intelligence } \\ \text { SIL } & \text { Systems Integration Labs } \\ \text { SUW } & \text { Surface Warfare } \\ \text { TACSIT } & \text { Tactical Situation } \\ \text { TADIXS-B } & \text { Tactical Data Exchange System Broadcast } \\ \text { TDDS } & \text { Tactical Data Distribution System } \\ \text { TDFA } & \text { Top-Down Function Analysis } \\ \text { TIBS } & \text { Tactical Information Broadcast System } \\ \text { TOC } & \text { Total Ownership Cost } \\ \text { TSC } & \text { Theater Support Command } \\ \text { UAV } & \text { unmanned aerial vehicle }\end{array}$

\section{References}

[1] P-8A Poseidon, Integrated Defense Systems, The Boeing Company, http://www.boeing.com/defense-space/military/p8a/index.html.

[2] Anderson, Torger J. "Vulnerability Reduction Features for Commercial Derivative Combat Aircraft," 47th AIAA/ASME/ASCE/AHS/ASC Structures, Structural Dynamics, and Materials Conference, 1 - 4 May 2006, Newport, Rhode Island.

[3] Guarneri, James M., "Establishing the Analytical Foundation: Multi-Mission Maritime Aircraft Platform Performance Assessment,” Johns Hopkins Applied Physics Lab (APL) Technical Digest, Volume 24, Number 3 2003, pages 263 to 269.

[4] Google images, http://images.google.com/imghp?hl=en\&tab=wi.

[5] Evans, Christopher L., "Multi-Mission Maritime Aircraft Acquisition Planning: Requirements Development and Maturation,” Johns Hopkins Applied Physics Lab (APL) Technical Digest, Volume 24, Number 3 2003, pages 292 to 296.

[6] Parasida, Tony and Rothback, Neal, "P-8A Program Update,” The Boeing Company, Paris Air Show 2009, http://www.boeing.com/paris2009/media/Presentations/june16/P8A_Paris_09_DEV7.pdf.

[7] P-8 Multimission Maritime Aircraft (MMA), GlobalSecurity.org, http://www.globalsecurity.org/military/systems/aircraft/p-8.htm.

[8] "P-8A Poseidon T-2 in Flight," G2 Solutions News Review: Analyzing the Business of Aerospace and Defense, 19 June 2009, http://g2globalsolutions.com/review/?p=1780

[9] Newsome, Larry, Rear Admiral U.S. Navy, "Multi-Mission Maritime Aircraft (MMA) Program Overview,” Pacific 2002 - United States and Australia Cooperation Conference, IDEEA Inc., Sydney, Australia, 2002.

[10] Eastburg, Steven R., Rear Admiral U.S. Navy, “A Warfighting Partnership: Aircraft and Carriers Ready for Tasking at Reduced Cost,” Naval Postgraduate School Presentations.

[11] Lilly, Trena C. and Russell, Bruce R., "The Multi-Mission Maritime Aircraft Design Reference Mission,” Johns Hopkins Applied Physics Lab (APL) Technical Digest, Volume 24, Number 3 2003, pages 257 to 262. 
[12] Tallant, Shane, Martin, Michael, and Hedrick, Scott, “Analysis of Contractor Logistics Support for the P-8 Poseidon Aircraft,” Naval Postgraduate School (NPS), Monterey, 5th Annual Acquisition Research Symposium: Creating Synergy for Informed Change, May 14-15, 2008 in Monterey, CA, 93943, http://www.dtic.mil/cgibin/GetTRDoc?AD=ADA493933\&Location=U2\&doc=GetTRDoc.pdf.

[13] Sweetman, Bill, “Swooping to Conquer,” Jane's Navy International, Maritime World Ltd., 2005.

[14] Iyyer, Nagaraja et al, “Aircraft Life Management using Crack Initiation and Crack Growth Models - P-3C Aircraft Experience,” International Journal of Fatigue, Volume 29, Issues 9-11, September-November 2007, Pages 1584-1607.

[15] Phan, Nam D., "P-3 Service Life Assessment Program (SLAP) - A Holistic Approach to Inventory Sustainment for Legacy Aircraft,” U.S. Navy, Naval Air Systems Command, www.corrdefense.org.

[16] “Boeing P-8A Poseidon Backgrounder,” Integrated Defense Systems, the Boeing Company, http://www.boeing.com/defense-space/military/p8a/docs/P-

8A_overview.pdf.

[17] Pharmer, James A., "The Challenges and Opportunities of Implementing Human Systems Integration into the Navy Acquisition Process,” Defense Acquisition Review Journal, February 2007, pages 278 to 291, http://www.dau.mil/pubs/ arq/2007arq/2007arq44/ARJ44_Pharmer.pdf.

[18] Achtellik, Paul, "P-8A “Poseidon" Collaborative Simulation and Stimulation for Electromagnetic Environmental Effects Test \& Evaluation,” the International Test and Evaluation Association (ITEA) Journal, 2008, volume 29, pages 17 to 21.

[19] Rumsfeld, Donald H., Secretary of Defense, "Annual Report to the President and the Congress,” Department of Defense, Office of the Executive Secretary, Annual Reports to the President and Congress, 2005, http://www.dod.mil/execsec/adr2005.pdf.

[20] Schenker, Fred, “A Process-Oriented (Practical) Approach to Program Office Systems Engineering Management Using the CMMI-AM as a Guide,” Carnegie Mellon Software Engineering Institute, 2005, http://www.sei.cmu.edu/library/assets/schenker.pdf.

[21] Andrews, A.M., "Science and Technology for Modular Systems," The Naval Research Advisory Committee, 2005, http://www.nrac.navy.mil/docs/2005_rpt_modular_ system.pdf.

[22] Hall, Dave, "Integrated Survivability Assessment (ISA) in the Acquisition Lifecycle," 45th AIAA/ASME/ASCE/AHS/ASC Structures, Structural Dynamics, and Materials Conference, April 2004, Palm-Springs, CA.

[23] Garber, Jean M. and Williamson, Arthur C., "Multi-Mission Maritime Aircraft Survivability in Modern Maritime Patrol and Reconnaissance Missions,” Johns Hopkins Applied Physics Lab (APL) Technical Digest, Volume 24, Number 3 2003, pages 304 to 309.

[24] Weisenbach, Michael R., "Update on the Joint Aircraft Survivability Program (JASP)," 49th AIAA/ASME/ASCE/AHS/ASC Structures, Structural Dynamics, and Materials Conference, 7 - 10 April 2008, Schaumburg, IL.

[25] Legg, Dave and Dolinar, Joe, "P-8A Dry Bay Fire Suppression System Development," Aircraft Survivability, Joint Aircraft Survivability Program Office, Spring 2008. 